\title{
市販サラミソーセージの菌類とペニシリン酸 生産性の検討
}

\author{
(昭和 50 年 5 月 21 日受理)
}

$\begin{array}{lll}\text { 高鳥浩介*1 } & \text { 高橋 患子*1 } & \text { 鈴木 敏 } \text { 正 }^{* 2} \\ \text { 宇田川俊一*3 } & \text { 倉田 浩*3 } & \end{array}$

\section{Mycological Examination of Salami Sausages in Retail Markets and the Potential Production of Penicillic Acid of Their Isolates}

\author{
Kosuke TAKatori*1, Keiko TAKahashi*1, Toshimasa SUZUKI*2, \\ Shun-Ichi UdAGAwA*3 and Hiroshi Kurata*3 \\ (*1Hatano Laboratory, Food and Drug Safety Center: Ochiai, Hatano-shi, Kanagawa; \\ *2Saitama Institute of Public Health: 639-1, Kamiookubo-higashi, Urawa-shi, \\ Saitama; ${ }^{*}$ National Institute of Hygienic Sciences: \\ 18-1, Kamiyoga 1-chome, Setagaya-ku, Tokyo)
}

\begin{abstract}
Mycological survey of Salami sausages in retail markets, 13 samples of mold-fermented type and 18 of natural fermented type, was carried out from viewpoints of food sanitation. Most important genus of fungi detected from the mold-fermented type Salamis was Penicillium, particularly representative of $P$. cyclopium, P. miczynskii, and $P$. viridicatum. These isolates might be brought from the artificial inocula during a manufacturing process of the Salamis. In the natural fermented type, more broader range of fungal groups were distributed: Cephalosporium sp., Mucor mucedo, $M$. racemosus, Aspergillus versicolor, Penicillium cyclopium, and others. Furthermore, when the populations of individual groups of fungi were considered, great differences were noted in the total amounts of Penicillium in the natural fermented Salamis as compared with those from the mold-fermented. Totally 23 strains of Penicillium, belonging in $P$. cyclopium, $P$. expansum, $P$. miczynskii, $P$. viridicatum, and other 3 species, were screened for production of penicillic acid (PA). None of the examined Penicillium strains yielded detectable amounts of PA in liquid shaking culture. It may be concluded from the above results and data of Ciegler, et al. (1972), that consumption of mold-fermented sausage does not represent a potential health hazard.
\end{abstract}

(Received May 21, 1975)

食品の污染菌類によるマイコトキシン産生は, 主とし て食品の貯蔵期間に大きく左右されるので, 生鮮食品に 比べて貯蔵食品は, マイコトキシン污染の危険にさらさ れる機会も多い。このような意味から従来穀類を中心と した食品が研究対象とされてきた。.タンパク性食品で は，新鮮な肉類よりも長期貯蔵を目的とする食肉加工品 (ハム,ソーセージ) ほどマイコトキシン污染の可能性

\footnotetext{
*1 食品薬品安全センター：神奈川県秦野市落合

*2 埼玉県衛生研究所：浦和市上大久保 639-1

*3 国立衛生試験所：東京都世田谷区上用賀 1-18-1
}

が深刻である.すなわち，欧米において食肉加工品由来 の菌類について aflatoxin, ochratoxin, sterigmatocystin, citrinin などの生産性が検索されている1). われわれは，近年輸入食品のうちで，加工上カビ付け をした，いわゆるカビ醱酵型サラミンーセージを含むサ ラミソーセージ類の安全性が問われたためこれらの市 販品試料について菌類分布を調へ，さらに主要分離菌株 について penicillic acid (PA) の産生能を検討した。

\section{実験材料および方法}

試料は市販カビ醅酵型サラミソーセージ13点, 自然醸 
Table 1. List of Salami Sausage Samples (Mold-fermented)

\begin{tabular}{|c|c|c|c|c|c|}
\hline \multirow{2}{*}{ No. } & \multirow{2}{*}{ Type } & \multirow{2}{*}{$\begin{array}{l}\text { Country } \\
\text { produced }\end{array}$} & \multicolumn{2}{|c|}{$\mathrm{pH}$} & \multirow{2}{*}{$\begin{array}{l}\text { Moisture contents } \\
(\%)^{*}\end{array}$} \\
\hline & & & Whole & Inner & \\
\hline 1 & Soft & Australia & 5.0 & 5.0 & 28.4 \\
\hline 2 & $"$ & " & 4.8 & 4.4 & 34.4 \\
\hline 3 & " & " & 5.6 & 5.0 & 29.4 \\
\hline 4 & " & " & 6.6 & 6.2 & 20.9 \\
\hline 5 & " & " & 5.8 & 5.6 & 30.3 \\
\hline 6 & " & " & 6.4 & 5.4 & 25.0 \\
\hline 7 & " & " & 5.2 & 5.0 & 26.3 \\
\hline 8 & $"$ & " & 5.4 & 5.0 & 25.2 \\
\hline 9 & $"$ & $"$ & 5.4 & 5.2 & 28.8 \\
\hline 10 & " & $"$ & 6.2 & 6.0 & 38.4 \\
\hline 11 & " & " & 5.0 & 5.0 & 30.8 \\
\hline 12 & $"$ & Austria & 6.6 & 6.4 & 17.4 \\
\hline 13 & " & Unknown & 5.6 & 5.6 & 20.3 \\
\hline
\end{tabular}

* By AOAC method

Table 2. List of Salami Sausage Samples (Natural-fermented)

\begin{tabular}{|c|c|c|c|c|c|}
\hline \multirow{2}{*}{ No. } & \multirow{2}{*}{ Type } & \multirow{2}{*}{$\begin{array}{l}\text { Country } \\
\text { produced }\end{array}$} & \multicolumn{2}{|c|}{$\mathrm{pH}$} & \multirow{2}{*}{$\begin{array}{c}\text { Moisture contents } \\
(\%)^{*}\end{array}$} \\
\hline & & & Whole & Inner & \\
\hline 1 & Dry & Denmark & 4.8 & 4.8 & 23.0 \\
\hline 2 & " & Japan & 5.2 & 5.2 & 22.4 \\
\hline 3 & Soft & " & 6.0 & 6.2 & 60.9 \\
\hline 4 & " & " & 5.0 & 5.0 & 53.5 \\
\hline 5 & $"$ & " & 5.6 & 5.8 & 55.2 \\
\hline 6 & $"$ & Australia & 5.0 & 4.8 & 36.6 \\
\hline 7 & $"$ & " & 5.8 & 5.8 & 42.5 \\
\hline 8 & " & " & 6.0 & 5.8 & 33.7 \\
\hline 9 & $"$ & Sweden & 5.0 & 4.8 & 30.3 \\
\hline 10 & $"$ & " & 4.0 & 4.0 & 30.5 \\
\hline 11 & " & " & 4.2 & 4.2 & 34.3 \\
\hline 12 & $" \prime$ & Finland & 4.8 & 4.8 & 19.9 \\
\hline 13 & " & " & 4.8 & 4.8 & 27.9 \\
\hline 14 & " & Norway & 5.0 & 4.8 & 30.6 \\
\hline 15 & $" 1$ & Canada & 4.0 & 4.2 & 32.6 \\
\hline 16 & " & " & 4.8 & 4.8 & 43.9 \\
\hline 17 & $"$ & New Zealand & 4.6 & 4.8 & 38.8 \\
\hline 18 & $"$ & Unknown & 5.2 & 5.0 & 35.5 \\
\hline
\end{tabular}

* By AOAC method

酵型サラミソーセージ18点で，種類はソフトがほとんど であった (Table 1, 2). 多くは輸入品で, 主としてオース トラリア，ニュージーランド，カナダ，デンマーク，フ ィンランド，ノルウェー，スウェーデン，オーストリア
産のものであった．供試試料の性状は次のようである. $\mathrm{pH}$ は全体部 (外表皮と内部), 内部ともに酸性で $5 \sim$ 6 の間であり，酸性度は若干全体部より内部で強い。含 水量は, 国産ソフト型の50\%以上を除いて, 大部分20 
Table 3. Fungal Groups Detected on Salami Sausage (PDA Medium)

\begin{tabular}{c|c|c|c|c|c} 
Mold-fermented & Penicillium & Aspergillus & Mucorales & Chrysosporium & Other fungi \\
\hline Whole & $12(92.3 \%) *$ & $1(7.7 \%)$ & $2(15.3 \%)$ & $1(7.7 \%)$ & $3(23.0 \%)$ \\
Inner & $9(69.2 \%)$ & $10(76.9 \%)$ & & & $2(15.3 \%)$
\end{tabular}

\begin{tabular}{c|c|c|c|c|c} 
Natural-fermented & Penicillium & Aspergillus & Mucorales & Cephalosporium & Other fungi \\
\hline Whole & $8(44.4 \%)$ & $7(38.9 \%)$ & $3(16.7 \%)$ & $4(22.2 \%)$ & $3(16.7 \%)$ \\
Inner & $2(11.1 \%)$ & $5(27.8 \%)$ & $2(11.1 \%)$ & & $1(5.6 \%)$
\end{tabular}

* Sample numbers and percentages for the detection of each group.

Table 4. Fungal Groups Detected on Salami Sausage (M40YA medium)

\begin{tabular}{c|c|c|c|c|c} 
Mold-fermented & Penicillium & Aspergillus & Mucorales & Chrysosporium & Other fungi \\
\cline { 1 - 3 } & $10(76.9 \%) *$ & $4(30.7 \%)$ & $2(15.3 \%)$ & $1(7.7 \%)$ & \\
Whole & $7.0(53.8 \%)$ & $10(76.9 \%)$ & & & $1(7.7 \%)$
\end{tabular}

\begin{tabular}{c|c|c|c|c|c} 
Natural-fermented & Penicillium & Aspergillus & Mucorales & Cephalosporium & Other fungi \\
\hline Whole & $6(33.3 \%)$ & $7(38.9 \%)$ & $3(16.7 \%)$ & $1(5.6 \%)$ & $2(11.1 \%)$ \\
Inner & $3(16.7 \%)$ & $6(33.3 \%)$ & $2(11.1 \%)$ & & $1(5.6 \%)$
\end{tabular}

* See Table 3.

$30 \%$ 台であった，

\section{菌類検 索}

試料を全体部と内部にわけ，それぞれから無菌的に5 $\mathrm{g}$ を秤取し, 隇菌0.05\%寒天水 $45 \mathrm{ml}$ を加兄, $3 \sim 5$ 分間ワーリングブレンダーで細砕し試料液を調製，希釈 平板法により分離培養を行った。分離用培地としては, バレイショ・グルコース寒天培地 (PDA：バレイショ $300 \mathrm{~g}$ の煮汁, グルコース $20 \mathrm{~g}$, 寒天 $20 \mathrm{~g}$, 水 $1000 \mathrm{ml}$, クロラムフェニコール $100 \mathrm{mg}$ 添加）と M40Y 寒天培 地（ショ糖 $400 \mathrm{~g}$, 麦芽エキス $20 \mathrm{~g}$, 酵母エキス $5 \mathrm{~g}$, 寒天 $20 \mathrm{~g}$, 水 $1000 \mathrm{ml}$ ) の 2 種類を用い, $25^{\circ}, 1 \sim 2$ 週間培養し, 出現した菌類を分離, 同定した.

\section{分離菌株の PA 生産性}

コーンスチープ液体培地（グルコース $50 \mathrm{~g} ，$ ペプトン $20 \mathrm{~g}$, コーンスチープ・リカー $3 \mathrm{~g}$, 水 $1000 \mathrm{ml}, \mathrm{pH}$ : 6.0）を用い， $25^{\circ} ， 5$ 日間， $120 \sim 130 \mathrm{rpm}$ で往復振と ら培養したろ液についてPAの分析を行い，その有無を 判定した。分析方法は培養ろ液 $20 \mathrm{ml}$ をとり，塩化ナ トリウム $2 \mathrm{~g}$ を加党, 酶酸エチル $20 \mathrm{ml}$ で 2 回抽出 し, 以後鈴木 ${ }^{2)}$ の方法潐じて操作し, 薄層クロマト グラフィー，ガスクロマトグラフィー，拈よび GC・マ ススペクトル分析を行った。 なお，対照としてPenicillium martensii PA 生産菌株 (69-GO-38) を用い， 同一条件下で培養し，PA 生産ならびに検出条件を検討
確認した。

\section{結果}

1. 菌類分布の概要 (菌群別)

$\mathrm{PDA}$ 培地および $\mathrm{M} 40 \mathrm{Y}$ 寒天培地に打ける菌群別出 現度数を Table 3 と 4 に示した. PDA 培地の場合, カビ醊酵型の全体部では Penicillium 属が 13 試料中 12 試料にみられ $92 \%$ と最も出現率が高く, Penicillium 属 以外のものはわずかに検出されたのみであった。内部で は, Penicillium 属は多少減小し 9 試料となり, 代わり にAspergillus 属が13試料中に 10 試料 $(77 \%)$ と高率 に出現した。自然酸酔型の全体部では，特に優先してい ると思われる菌類はなく, pや多いものとしてPenicillium 属が18試料中 8 試料に, Aspergillus 属が 7 試 料中に検出された。年のほか, Cephalosporium 属が 4 試料にみられた。内部では菌類検出試料数はさらに減少 し，Aspergillus 属が5 試料にみられただけであった。

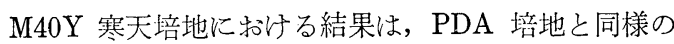
傾向にあり, カビ醱酵型の全体部では, Penicillium 属 が，内部ではAspergillus 属が多かった。自然醴酵型 の全体部, 内部とも菌分布は PDA 培地と大体同様であ った.

なお，その他に検出された菌としては，Arthrinium， Cladosporium,Fusarium, Paecilomyces, Scopulariopsis, Trichoderma などの諸属であった. 

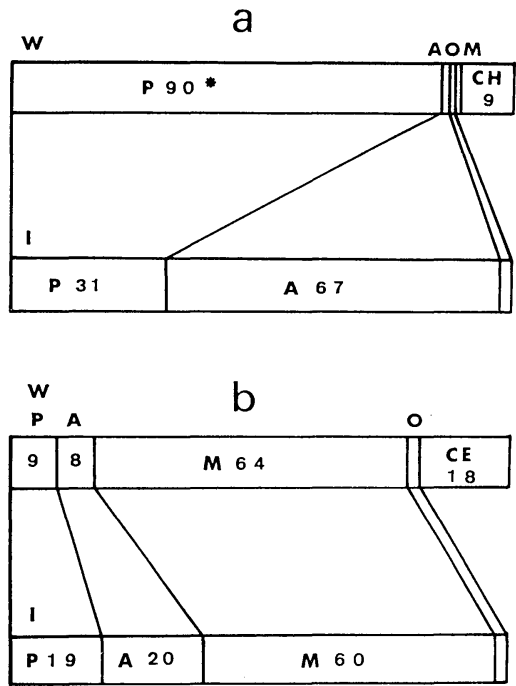

Fig. 1. Constitution and total counts of detected fungi on salami sausage (PDA medium)

Fungal counts (range): mold-fermented (whole), av. $215(4-1160) \times 10^{2} / \mathrm{g}$; (inner), av. $4(1-34) \times 10^{2} / \mathrm{g}$; natural-fermented (whole), av. $32(1-350) \times 10^{2} / \mathrm{g}$; (inner), av. $1(1-11) \times 10^{2} / \mathrm{g}$.

Abbreviations: a, mold-fermented; b, natural-fermented; W, whole; I, inner; P, Penicillium; A, Aspergillus; M, mucorales; CE, Cephalosporium; $\mathrm{CH}$, Chrysosporium; 0 , other fungi.

* Percentages for each group.

\section{2. 菌類検出量（菌群別）}

以上の結果を， 1 試料当たり平均検出総量と, 各菌群 の占める検出量構成の面から表示したのが Fig. 1 と 2 である.

PDA 培地のカビ醱酵型をみると, 平均検出総量は全 体部が $215 \times 10^{2}$ コニー/g で，内部の約50倍量もあり, なかでも全体部で検出された Penicillium 属は総量の $90 \%$ 占めていた。自然䣫酵型の平均検出総量はカビ醱 酵型に比べ全体部は約 $1 / 7$ と少なく, 内部は約 $1 / 4$ となっ ていた. Mucorales が全体部, 内部ともに優先菌となっ ているのが特幑である.

M40Y 寒天培地も PDA 培地と同傾向にあり，力ビ醱 酵型では全体部が内部に比べ非常に多く，また自然醇酵 型とカビ醱酵型では全体部での総量で比較すると，自然 醴酵型はカビ醱酵型の約 $1 / 7$ となっていた。

\section{3. 主要菌種の分布と検出量}

主要菌についてカビ醊酵型, 自然醱酵型の PDA 培地 にお㹁る結果を Table 5 に示した。

カビ醱酵型全体部の主要菌は, 12 試料に検出された
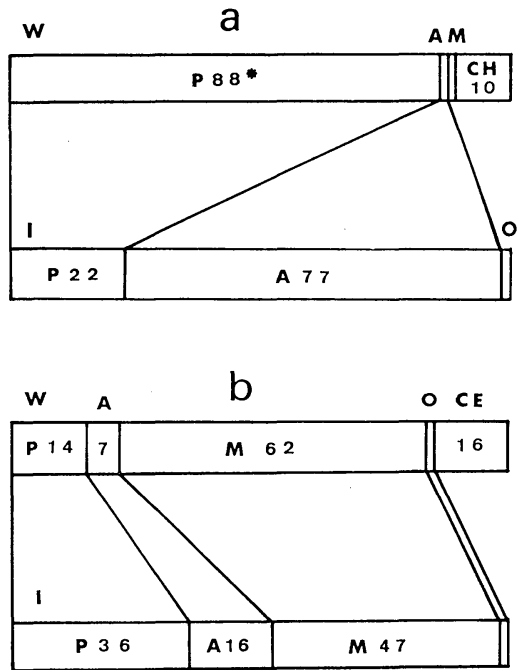

Fig. 2. Constitution and total counts of detected fungi on salami sausage (M40YA medium)

Fungal counts (range): mold-fermented (whole), av. $178(6-718) \times 10^{2} / \mathrm{g}$; (inner), av. $1(1-3) \times 10^{2} / \mathrm{g} ; \quad$ natural-fermented (whole), av. $25(1-250) \times 10^{2} / \mathrm{g} ;$ (inner), av. $1(1-9) \times 10^{2} / \mathrm{g}$.

Abbreviations: See Fig. 1.

Penicillium cyclopium および 8 試料の P. miczynskii を初め P. viridicatum, Mucor racemosus, Chrysosporium sp. であった。 また内部では, 菌種において Aspergillus 属が多くなり, 特に Eurotium spp.を初 め A. candidus, A. fumigatus, A. versicolorなどが 認められた. Penicillium 属では P. cyclopium が多 く出現したが，Mucoralesは全く分離されなかった。

自然醱酵型は一般に菌類検出頻度が少なかったが全体 部で分離された主要菌は, Cephalosporium sp., Mucor mucedo, M. racemosus, A. versicolor, P. cyclopium であった。また，Mucorales ではほとんどが Mucor 属 であり，わずか 1 試料に Absidia 属がみられたにすぎ なかった。 内部では全体部に比べ，さらに菌種が少なく なっているが, Aspergillus 4 種を検出した点が注目さ れる。

\section{4. 主要ソーセージ分離菌株の PA 生産性}

主としてスターターと考えられるカビ醱酵型ソーセー ジ分離株を中心に検索した結果, Table 6 に示すように 23菌株のすべてに PA 産生能は認められなかった.な お，対照として用いた P. martensii 69-GO-38 株から は $0.06 \sim 0.07 \mathrm{mg} / \mathrm{ml}$ の収量で PA の生産性が確認さ れた。 
Table 5. Frequency and Distribution of Representative Fungi on Two Types of Salami Sausage (PDA Medium)

\begin{tabular}{|c|c|c|c|c|}
\hline \multirow[t]{2}{*}{ Fungi } & \multicolumn{2}{|c|}{$\begin{array}{l}\text { Mold-fermented } \\
\text { (13 samples) }\end{array}$} & \multicolumn{2}{|c|}{$\begin{array}{l}\text { Natural-fermented } \\
\text { (18 samples) }\end{array}$} \\
\hline & Whole & Inner & Whole & Inner \\
\hline Penicillium citrinum & & & $+(1)$ & \\
\hline P. cyclopium & 册 $(12) *$ & $+(6)$ & H (6) & $+(2)$ \\
\hline$P$. expansum & $+(1)$ & & & \\
\hline P. frequentans & & & $+(1)$ & \\
\hline P. janthinellum & & & $+(1)$ & \\
\hline P. miczynskii & 冊 (8) & & $+(2)$ & \\
\hline$P$. viridicatum & H (3) & & $+(1)$ & \\
\hline Penicillium sp. & & $+(1)$ & & \\
\hline Talaromyces wortmanii & & $+(3)$ & & \\
\hline Aspergillus candidus & & $+(5)$ & $+(4)$ & $+(3)$ \\
\hline A. fumigatus & & H (1) & $+(2)$ & \\
\hline A. niger & & & $+(1)$ & $+(1)$ \\
\hline A. versicolor & $+(1)$ & H $(6)$ & H (3) & $+(1)$ \\
\hline Aspergillus spp. & & $+(3)$ & $+(1)$ & \\
\hline Eurotium spp. & & $+(8)$ & $+(6)$ & $+(2)$ \\
\hline Cephalosporium spp. & $+(1)$ & & H (4) & \\
\hline Chrysosporium sp. & & 冊 (1) & & \\
\hline Mucor fragilis & $+(1)$ & & & $+(1)$ \\
\hline M. mucedo & & & H (2) & \\
\hline M. racemosus & H (2) & & H (2) & $+(1)$ \\
\hline
\end{tabular}

* Fungal counts: +, 1; H, 1 5; H, 5 10; H, 10 50; HW, 50 ( $\left(\times 10^{2} / \mathrm{g}\right)$

( ), numbers of sample detected

Table 6. Penicillic Acid (PA) Production by Penicillium Species Isolated from Salami Sausage

\begin{tabular}{l|c}
\multicolumn{1}{c|}{ Species } & $\begin{array}{c}\text { No. of PA producers } \\
\text { for isolates examined }\end{array}$ \\
\hline$P$. cyclopium & $0 / 9$ \\
$P$. miczynskii & $0 / 5$ \\
$P$. viridicatum & $0 / 4$ \\
$P$. frequentans & $0 / 2$ \\
P. citrinum & $0 / 1$ \\
$P$. expansum & $0 / 1$ \\
$P$. janthinellum & $0 / 1$ \\
\hline Total & $0 / 23$
\end{tabular}

\section{考察}

1. カビ醇酵型サラミソーセージについて

Penicillium 属が検出菌のほとんどを占め, 特に全体 部と内部との菌構成の違いから Penicillium の大部分 は外表皮に由来することが明確であり，これらの菌によ
ってカビ付け加工されていることが分かる．本研究の結 果で浪, P. cyclopium が多く, 次いで P. miczynskii および若干の P. viridicatum がみられた。このような

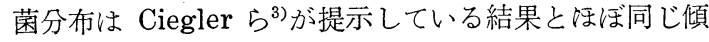
向にあるが，彼等が多く検出したという P. simplicissimum, P. expansum, P. janthinellum は若干ない しほとんど検出されなかった。

Penicillium 属以外では Chrysosporium sp. が 1 試 料に多く分離された。Chrysosporium 属が肉製品に普 通にみられることは一般に知られている4). カビ付けの 対象菌となっていたかは不明であるが，サラミソーセー ジの性状からみて，この菌は異常躌酵がたまたま菌発育 に好条件となったために, 熟成過程で他の菌に優先し多 く分離されたものと思われる.

\section{2. 自然䤑酵型サラミソーセージについて}

カビ醱酵型に比較して全体部・内部とも菌量は少なく 全体部では, Penicillium および Aspergillus 属が試 料の約半数より分離され，カビ醱酵型と比べ出現菌に大 きなへだたりがない，そのほか，Cephalosporium， Mucoralesなど出現菌群もより広範囲にわたっている。 
菌種についても P. cyclopium, Cephalosporium sp., A. candidus, A. fumigatus, Eurotium spp., Mucor mucedoなど比較的広い種類にわたって分布している. また，熟成工程中での外表皮の着生菌として Mucor racemosus, M. mucedo を中心とした Mucorales が少 なからず認められ，生肉に多いこれらの菌が自然発生す ることも現象として当然であろら ${ }^{4)}$. これらの特徵は自 然醱酵型の菌類分布のパターンとして考えられるところ であるが，西田ら ${ }^{5)}$ がドライソーセージの主要菌類がわ ずかに Penicillium 1 属のみ高率に分離されるとし, 外表皮から P. notatum, P. chrysogenum, 練肉から P. claviforme を検出報告している点とは幾分異なる 結果である.すなわち, 西田らの熟成過程中での検索 と市販品の場合とでは菌内容に相違があるとも思われ る.

\section{3. カビ䤑酵型サラミソーセージの Penicillium 属} 安全性について

ソーセージの菌分布を穀類の場合と比較すると, タン パク食品特有の菌種, Penicillium 属の AsymmetricaDivaricata 群, Cephalosporium 属, Chrysosporium 属, Mucor 属, Aspergillus fumigatus などが特定菌 として分布し，なかでも加工菌としての Penicillium 属の存在は量的な点からも注目された。すなわち, カビ 醴酵型のように加工上カビ付け後, 熟成させて製造した ソーセージが食品衛生上安全であるかどうかは，この種 の食品が最近多量に輸入市販されていることからも早急 に検討を要する問題である。

スターターとして Penicillium を用いることの意義 は, ソーセージに対する風味づけ, Aspergillus のよう な雑菌による変敗あるいはマイコトキシン生産の予防に ある，例えば，八ム，ソーセージなど食肉加工品から分 離された A. flavus, A. ochraceus, A. versicolor な ぞの菌株の一部は熟成中の加工品に接種した場合, 条件 次第ではそれぞれ aflatoxin, ochratoxin, sterigmatocystin などの生産性を示すと報告されている1). した がって, 例え少量でもこれらの雑菌の污染は好ましくな い. また Wu, et $a l .{ }^{6}$ )によれば, 食肉加工品から分離 された Aspergillus, Penicillium の143株について鶏 胚に対する毒性を検索した結果, A. ruber, A. repens, $A$. sydowi, A. restrictus, A. amstelodami, $A$. chevalieri, A. fumigatus, $P$. expansum, $P$. notatum, P. brevi-compactum などの菌株に毒性を示すものがあ るという.

スターターとしての条件は, 毒性がなく, 生育が早 く, 厚い菌系層をソーセージ外表皮に形成し, 芳香をつ けることで, 特に毒性面で P. expansum の加工菌とし ての可否が欧米で議論されている. 現在までの研究で は, 肉類における $P$. expansum などの patulin 生産 は基質としての肉タンパク中の sulfhydryl 基が不活化
するために認められず，P. expansum の使用は安全と されている7).

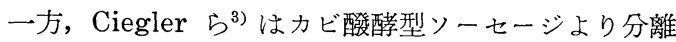
した Penicillium 346菌株について PA の産生能を調 べ，その約 $10 \%$ に当たる34菌株から液体培養で PA 産生 能が認められたと報告している. しかし，今回分離した Penicillium 23菌株はすべて PA の生産は認められず, また Ciegler らの結果でも PA 生産性を示す 5 株につ いてソーセージに再接種し培養したところではソーセ一 ジ上においてPAの生産が認められなかったことを考慮 すると, 現在輸入されているカビ醱酵型サラミソーセー ジなどは食品衛生上まず安全であると考えてよい.

ソーセージ由来の Aspergillus については, 毒性の 面でさらに今後の検討を必要とする。

本研究を行うに当たり, 実験上の便宜を与えて下さっ た食品薬品安全センタ一秦野研究室長岩原繁雄博士, 埼 玉県衛生研究所食品衛生部長渡辺昭宣氏，ならびに同食 品衛生部第一科長能勢憲英氏に対し厚くお礼申し上げ る.

文献

1) Bullerman, L. B., Hartman, P.A., Ayres, J.C.: Appl. Microbiol., 18, 718 (1969); Escher, F.E., Koehler, P.E., Ayres, J.C.: ibid., 26, 27 (1973); Halls, N. A., Ayres, J. C.: ibid., 26, 636 (1973); Wu, M. T., Ayres, J. C., Koehler, P. E.: $\quad$ ibid., 27, 427 (1974); Leistner, L., Tauchmann, F.: Fleischwirtschaft, 50, 965 (1970); Alperden, I., Mintzlaff, H. -J., Tauchmann, F., Leistner, L.: ibid., 53, 707 (1973).

2) 鈴木敏正, 藤本義典, 渡辺昭宣, 能勢憲英, 星野 庸二, 小林 進, 田中章男, 菊池好則, 菅谷彰子: 食衛誌. 15, 280 (1974).

3) Ciegler, A., Mintzlaff, H. -J., Weisleder, D., Leistner, L.: Appl. Microbiol., 24, 114 (1972).

4) Ayres, G.: "Microbiological quality of foods" p. 132 (1963), Academic Press, N.Y. and London; Semeniuk, G., Ball, W.C.: Iowa Acad. Sci., 44, 37 (1937); 稲垣尚起：衛生試 報。79，293，297 (1961); 一言 広, 諸角 聖, 和宇慶朝昭, 善養寺 浩：都衛研年報. 24,41 (1972).

5) 西田 博, 清水隆雄, 保坂弘文, 山口東十, 富士 川明彦: New Food Industry, 12(8), 53 (1970).

6) Wu, M. T., Ayrse, J.C., Koehler, P.E.: Appl. Microbiol., 28, 1094 (1974).

7) Hofmann, K., Mintzlaff, H.-J., Alperden, I., Leistner, L.: Fleischwirtschaft, 51, 1534 (1971); Alperden, I., Mintzlaff, H. -J., Tauchmann, F., Leistner, L.: ibid., 53, 566 (1973). 